\title{
STUDIES ON THE BINTURONGS (ARCTICTIS BINTURONG) IN CAPTIVITY AT THE ARIGNAR ANNA ZOOLOGICAL PARK, VANDALUR
}

\author{
C. Arivazhagan ${ }^{1}$ and K. Thiyagesan ${ }^{2}$ \\ ${ }^{1}$ Indian Institute of Science Field and Research Station, Masinagudi, The Nilgiris, Tamil Nadu, India. \\ ${ }^{2}$ Department of Zoology, A.V.C. College, Mannampandal, Mayiladuthurai, Tamil Nadu, India.
}

\begin{abstract}
Captive conditions of three Binturongs Arctictis binturong (one female and two males) at the Arignar Anna Zoological Park, Vandalur were studied during December 1995 to February 1996. Enclosure design and dimensions, environment of the enclosure, activity patterns and enclosure use of the animals and diet of the animals were studied. Improvements for enclosure design and environment have been suggested. The animals were observed for 250 hours and 3990 recordings were made on their behaviour. Based on such an intensive study. The suggestions were (i) Provision of an outdoor enclosure, (ii) Psychological enrichment of the enclosure, (iii) Proper maintenance of temperature and humidity, (iv) Separation of old male to another enclosure, (v) Keeping the young male and female in isolation of old male to separate but adjoining enclosures and (vi) Modifications in the diet of the animal.
\end{abstract}

\section{Key words}

Binturong, Arctictis binturong, captivity, Arignar Anna Zoological Park, AAZP, enclosure design, psychological enrichment, diet, nutrition, activity pattern, Liberec Zoo, Glasgow Zoo, National Zoological Park, Washington

\section{Introduction}

The general aims and objectives of zoos are recreation, scientific investigation, education, breeding and conservation, with the relative importance of these aims varying with various stages of the history of zoos and different zoos. Zoos have been originally set up mainly for recreation and entertainment, of course with opportunities for some scientific investigations and a limited learning. At the Arignar Anna Zoological Park (AAZP), Vandalur, Chennai, Binturongs Arctictis binturong have been kept in captivity. In spite of various efforts by the zoo authoritities, the Binturongs do not breed here, and the present study was primarily aimed at evaluating the captive conditions for the improvement of the same so as to provide a congenial atmosphere for the animals to breed. Earlier accounts on the breeding requirements were by Bulir (1972) at the Liberec Zoo, Kuschinski (1974) at the Glasgow Zoo and by Xanten et al. (1976) at the National Zoological Park, Washington. Enclosure dimensions, close monitoring of behaviour especially oestrus,

Received 20 May 2000

Accepted 1 October 2000 provision of nest boxes, introduction and separation of pairs at the appropriate time, nutrition and care of young were the key points addressed by the above reports.

Behavioural observations are key to the understanding of the well being of animals in a zoo. By studying their activities and interaction in a captive condition, better management is possible. Observations on the state (or condition, or biology) of an animal within its captive environment is fundamental. The state of an animal i.e., its reproductive output, feeding frequency, cage use, etc., will have physiological and behavioural components and problems associated with them in the captive conditions can be detected by observation. Records of behaviour could, in theory, include all observations of all that an animal does in relation to its environment i.e., cage structure, cage mates, food, etc., and changes in that environment. These behavioural researches can be conducted without expensive apparatus and without disturbing or invading the animal physically or mentally. Further, behavioural studies, such as time-activity budget studies, in captive conditions can aid in understanding the animal's requirements better as activity budget analyses have been used 
in determining ecological, behavioural and physiological adaptations of animals (Kleiman, 1974; Roberts, 1989). A successful exhibition of captive animals is the one which caters for biological needs, for behaviour and for health including nutrition and disease free conditions. The exhibit must give an environment enriched to as near nature as possible.

Environment is often to mean only the space, of the cage or enclosure, but it includes the substrate and topography, hiding sites, vantage and territorial marking points, plants, areas of water and logs, as well. Roberts (1989) has stated that specific housing environmental condition and management practices are important and so the assessment of the use of different sites in the enclosure is essential to assess the animal's well-being in an enclosure.

Another important aspect of successful keeping of animals in captivity is nutrition. The ideal diet of an animal in captivity should be free of harmful microorganisms, nutritionally sound and parasite free; it should be of sufficient quantity, sufficient quality, free from deleterious effects, acceptable (identifiable and palatable) and digestible, and easily and cheaply obtained and stored. A good feed must be based on four basic nutrient states for all mammals: growth, maintenance, gestation and lactation. From the foregoing account, it is clear that successful animal keeping can best be evaluated by studying the animals' behaviour, enclosure details in comparison to their basic requirements, food and feeding and the environment of the enclosure. So, in order to identify the breeding requirements of binturongs, a study was conducted of the binturongs kept in a glass-viewed enclosure at AAZP, and the primary objectives of the study were:

1. To evaluate the present captive condition of the animals at AAZP in comparison with the basic requirements stated in literature;

2. To study the activity pattern and enclosure use especially with reference to breeding activities of binturongs at AAZP; and 3. To investigate the cause of non-breeding by binturongs at AAZP and suggest suitable recommendations.

\section{Systematics and distinctive characters of binturong}

The systematics and distinctive characters of binturong, based on Prater (1971) is given below.

\section{Systematics}

Class: Mammalia

Order: Carnivora

Family: Viverridae

Genus: Arctictis

Species: binturong

Race in India: albifrons (F. Cuvier)

\section{Size}

Head and body, $2 \mathrm{ft} 6$ in $(75 \mathrm{~cm})$ to $3 \mathrm{ft}(90 \mathrm{~cm})$; tail $2 \mathrm{ft} 4$ in $(70 \mathrm{~cm})$.

\section{Distinctive characters}

The binturong is easily distinguished from other civets. Its tuffed ears, its long shaggy coat suggestive of a bear, its tail markedly thick at the base and covered with large bristling hairs, longer than those of the coat, are distinctive. Colour, very variable: mostly black but an intermingling of partly white and buff hair may give the coat a grizzled appearance. In some animals the white and buff is so pronounced that the coat takes a straw coloured or grey tinge.

\section{Distribution}

In India, the range covers Nepal, Sikkim, Bhutan, Assam, extending into Myanmar and the Malay countries. Two races are recognised; the Indian form is said to be distinctive in its fuller and more luxuriant winter coat and a more marked tendency to a grizzled coloration.

\section{Habitat}

The binturong is a creature of dense forests. It is mainly arboreal and spends the day curled up in a hole in a tree, its head tucked well under its bushy tail. These animals come out at dusk to seek their food. Their movements through the trees are slow and deliberate, but they climb with ease with the tail to aid in climbing. The tail, very muscular at the base, is prehensile at the tip and is hitched round a branch as an anchorage, particularly when descending. Baby binturongs are able to support themselves by the extremity of the tail alone. Like other civets, binturongs are omnivorous, living on small animals, birds, insects and fruits. When on the prowl they are said to grunt and to make a hissing sound by expelling air through partly opened lips. From the build of the animal it would seem that most of their food is obtained in trees. The species, though particularly fierce, when taken young is easily tamed, becoming very gentle and playful. Because of their secretive nocturnal mode of life, the animals are rarely seen and nothing is known of their breeding habits (Prater, 1971).

\section{Materials and Methods}

\section{Binturongs at the AAZP and their enclosure}

There are three binturongs at the AAZP -- one female and two males. The female is about $4-5$ years old and weighs $14 \mathrm{~kg}$ (approximate). Among the males, one is old of about 10-11 years of age, and weighs $16 \mathrm{~kg}$ (approximate). They are kept in a single glass viewed enclosure. The enclosure measurements are $3 \mathrm{x}$ $3.1 \times 2 \mathrm{~m}$.

Temperature variations in the enclosure were measured by means of a thermometer and the humidity by means of a hygrometer. To study the enclosure use, the enclosure was arbitrarily divided into 13 tentative parts (Fig. 1). 


\begin{tabular}{|l|l|l|}
\hline F1 & F4 & F7 \\
\hline F2 & F5 & F8 \\
\hline F3 & F6 & F9 \\
\hline
\end{tabular}

Figure 1. Floor of the binturong enclosure at the AAZP, Vandalur Showing tentative blocks used for recording the enclosure use patterns of the animals.

In Figure 1,

F1-F9 = Blocks of the floor

$\mathrm{S}=$ Place where there was a stump placed inside the enclosure

In addition to the above parts on the floor of the enclosure, two cages $(\mathrm{C} 1$ and $\mathrm{C} 2)$ and a window (W) on the wall of the enclosure were also identified and all the thirteen locations viz., F1$\mathrm{F} 9, \mathrm{Cl}-\mathrm{C} 2, \mathrm{~S}$ and $\mathrm{W}$ were evaluated for their relative use by the three binturongs.

\section{Behavioural studies}

The behaviour of the binturongs were monitored from December 1995 to February 1996 by scan sampling method of Altman (1974). The hours in a day were divided into 3-hour time blocks, viz., 0600-0900, 0900-1200, 1200-1500, 1500-1800, 1800$2100,2100-2400,2400-0300$ and $0300-0600$ hrs. Observations in a day were restricted to alternate time blocks and the left out time blocks were covered in the next day. Half-hour sampling periods which consisted of 20 minutes rest, were used to collect data on various behavioural features of the animals. At first an ethogram was developed and then the activity data was recorded in a proforma designed based on the ethogram.

\section{Evaluation of nutritional and breeding requirements}

Data on food and feeding were collected simultaneously while doing behavioural studies. The nutritional conditions and breeding facilities available were compared with standard requirements specified by Bulir (1972), Kuschinski (1974) and Xanten et al. (1976).

Shannon-Weiner Diversity Index (H') (Shannon-Weiner, 1949) was calculated by the formula

$\mathrm{H}^{\prime}=-\sum \mathrm{p}_{\mathrm{i}} \log \mathrm{pi}$

Where $p_{i}$ is the proportion of the 'I'th item in the total diet/range of activities

\section{Result and Discussion}

\section{Enclosure dimensions and environment}

Three binturongs were kept in an enclosure of $3 \times 3.1 \times 2 \mathrm{~m}$. There was no outdoor enclosure available to the animals. This is a serious drawback as descriptions of binturong enclosures in other zoos with breeding records always had an outdoor enclosure (Bulir, 1972; Kuschinski, 1974; Xanten et al., 1976). The enclosure dimensions reported by Kuschinski (1974) for a pair of binturongs were a $6 \times 6 \times 3 \mathrm{~m}$ outdoor enclosure and two inside compartments each measuring about $1 \times 1 \times 1 \mathrm{~m}$. Similarly the enclosure dimensions given by Xanten et al. (1976) for the binturongs at the National Zoological Park, Washington were very large as there was a $3.0 \times 5.4 \times 2.4 \mathrm{~m}$ height outdoor enclosure and concrete shelter of $1.06 \times 0.91 \times 1.06 \mathrm{~m}$ for a pair of binturongs. So, it is suggested that an outdoor enclosure of at least $5 \times 5 \times 5 \mathrm{~m}$ should be annexed to the present inside compartment.

The temperature at the enclosure ranged between $24^{\circ} \mathrm{C}$ and $32^{\circ} \mathrm{C}$ and the humidity from 40 per cent to 60 per cent. These values were very high when one considers the report of Bulir (1972) on the binturongs enclosure at the Liberec Zoo where the average temperature ranged between $18^{\circ} \mathrm{C}\left(64^{\circ} \mathrm{F}\right)$ to $24^{\circ} \mathrm{C}\left(75^{\circ} \mathrm{F}\right)$ only. This again showed improper enclosure environment for the binturongs at AAZP.

Another important shortcoming with reference to psychological enrichment of the enclosure is that there is only one stump, even though the binturongs are arboreal in habit (Prater, 1971). Furnishing of binturong enclosures with lot of branches as an important way of psychological enrichment had been suggested by Xanten et al. (1976), as well. So, it is suggested that more psychological enrichment should be done at the binturong enclosure at AAZP.

\section{Activity pattern}

Binturongs at the AAZP were observed for 250 hours and 3990 recordings were made on their behavioural repertoire. The following were the major behavioural types recorded.

Moving, locomoting: As the space of the enclosure was small this was repetitive movement for majority of time.

Resting: Sitting or lying down with eyes closed or open and not exhibiting any other behaviour and this included sleeping as well.

Fighting: Striking or biting another animal.

Drinking and feeding: As implied

Self-grooming: Licking, chewing and/or cleaning and scratching self with hind paws.

Smelling_(Inanimate sniffing): Orienting to and apparently sniffing an inanimate object.

Vocalization: Animal orients to another and emits sound.

The above behavioural types were grouped into six categories viz., 


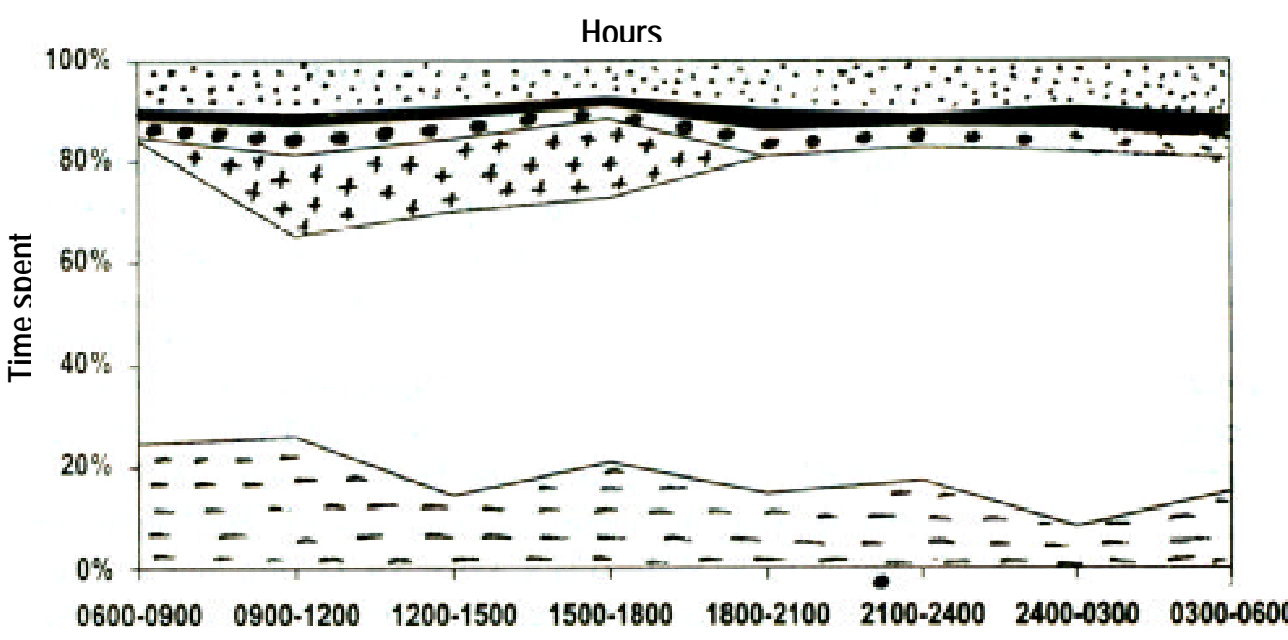

Goving $\square$ Resting $\Phi$ Feeding Agnostic Q Reproductive EOthers
Figure 2. Time activity pattern of the binturongs (all the three animals grouped together) at the $A A Z P$, Vandalur.
1. Moving; 2. Resting; 3. Feeding; 4. Reproductive behaviour, including smelling and vocalization only; 5. Agnostic behaviour including fighting and other hostile activities; 6. Others including, grooming, licking, crawling, etc.

Activity pattern of the binturongs are given in tables 1-4 and shown in fig. Overall, the binturongs spent about 60 per cent of their time resting 17.6 per cent moving, 5.9 per cent feeding, 4.4 per cent on agnostic activities (Fig. 2; Table 1). Moving, feeding and agnostic behaviour were highest during 0900-1200 hrs; resting was highest during 0000-0300 hrs; reproductive activities were more during 0300-0600 hrs and "other" activities were more or less uniform throughout the day. A comparison of the diurnal (daytime) and nocturnal activity revealed that moving and feeding were comparatively higher during daytime than night time, while resting, agnostic behaviour, reproductive behaviour and "other" activities were higher during night time. However, the activity pattern did not vary remarkably between day time and night time with only feeding being absent during night time.

The old male binturong spent 67.5 per cent of its time resting (Fig. 3; Table 2). It moved more during 1500-1800 hrs and feeding activity was also highest during that time. This was in accordance with Prater (1971) who stated that the binturongs come out during dusk to seek their food. On the other hand the young male and the female binturongs fed more during 09001200 hrs (Figs. 4 \& 5; Tables 3 \& 4) coinciding with feeding time of the animals at the zoo.

The young male exhibited more agnostic behaviour (5.5\%) when
Figure 3. Time activity pattern of the binturong (old male) at the $A A Z P$, Vandalur.
Hours

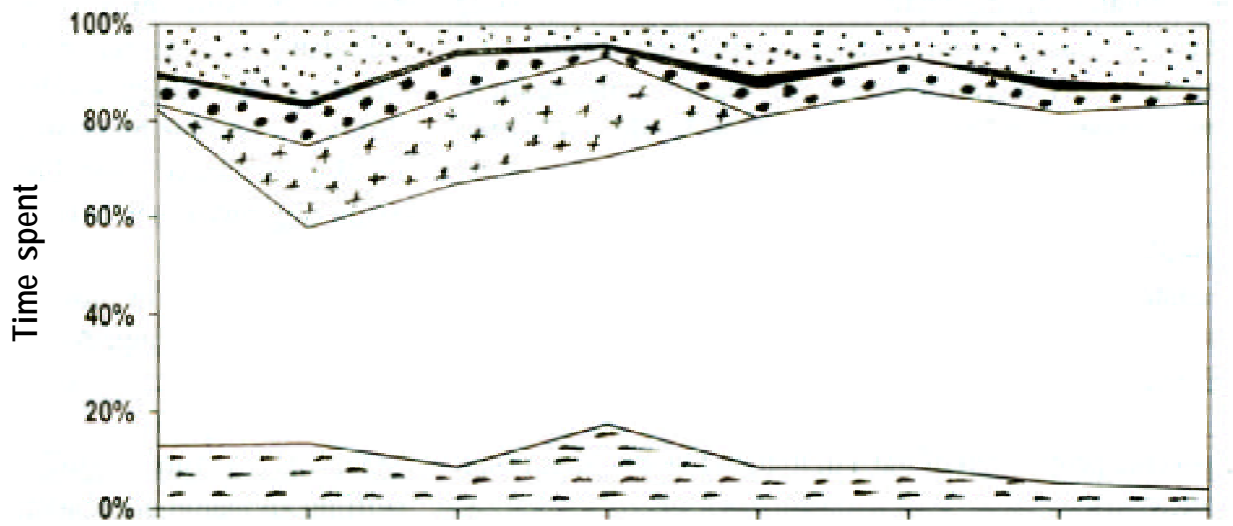

$0600-0900 \quad 0900-1200 \quad 1200-1500 \quad 1500-1800 \quad 1800-2100 \quad 2100-2400 \quad 2400-0300 \quad 0300-0600$

Moving $\square$ Resting $\$$ Feeding $\$$ Agnostic $\square$ Reproductive $\mathbf{B}$ Others 
Figure 4. Time activity pattern of the binturong (young male) at the $A A Z P$, Vandalur.

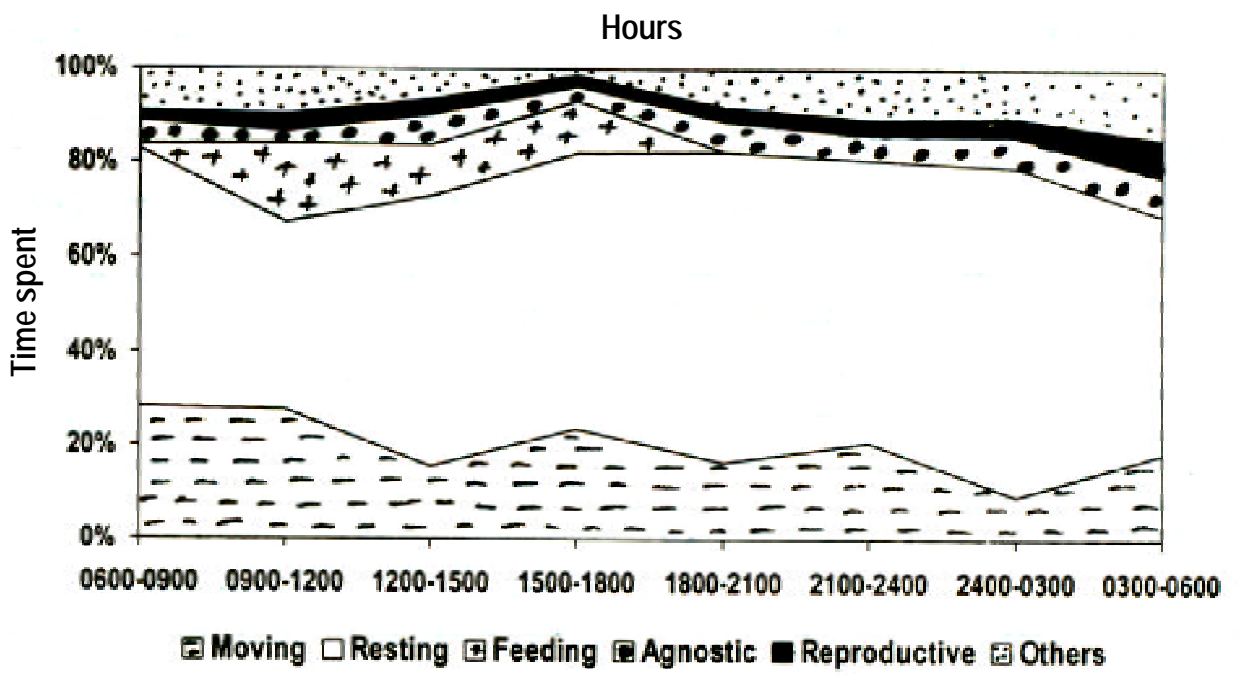

compared to the other two animals (Tables $2,3 \& 4$ ). This was understandable as it was the dominant member of the group. The old male exhibited very low reproductive behaviour $(1.7 \%)$ when comppared to the young male $(3.7 \%)$ and the female (4.1\%) (Tables 2, 3 \& 4).

In general, observations on the behaviour of the binturongs indicated that they were not in good psychological condition as they spent most of their time inactive and exhibited very low percentage of reproductive behaviour. Mating in binturongs under captive conditions have been reported in February, March, July and November (Gensch, 1963; Kuschinski, 1974; Xanten et al, 1976). By using birth dates reported by Bulir (1972) and Kuschinski (1974) and known gestation period, it might also be assumed that mating might have taken place in January, May,
June and September as well. So, the absence of any a reproductive sign except few behaviours in the binturongs during the study period at AAZP is intriguing, since binturongs are non seasonally polyestrous (Xanten et al., 1976). So, it is suggested that the male and female binturongs should be separated and kept in separate but adjoining enclosures until their behaviour shows signs that they are ready to be put together and their introduction should always be closely monitored. Such a method yielded good results 'when experimented by Xanten et al. (1976) at the National Zoological Park, Washington. Kleiman (1974) also stressed the importance of such behaviour studies on the species which are rare and whose survival depends upon captive breeding programmes.

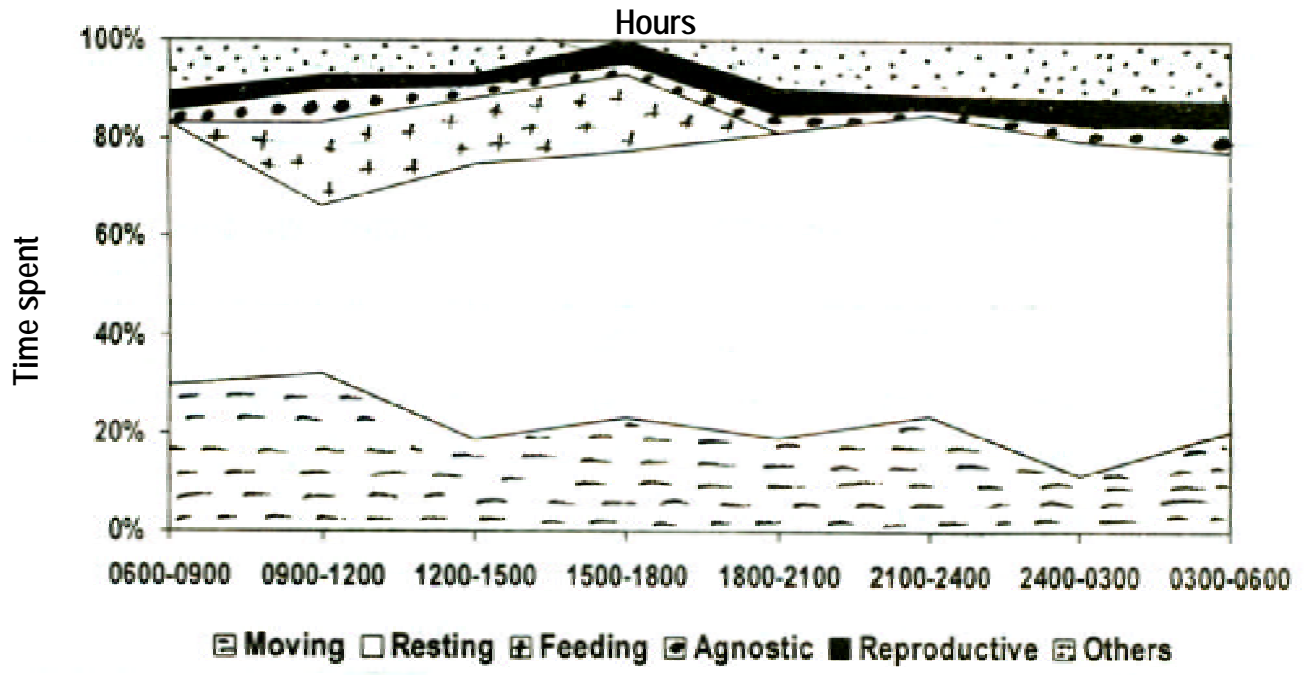

Figure 5. Time activity pattern of the binturong (female) at the AAZP, Vandalur. 
Table 1. Time activity pattern (percent time spent) of Binturongs (all the three animals grouped together) at the AAZP, Vandalur during December 1995 to February 1996.

\begin{tabular}{|c|c|c|c|c|c|c|c|c|c|}
\hline \multirow[t]{2}{*}{ Activity } & \multirow[b]{2}{*}{$0600-0900$} & \multirow[b]{2}{*}{$0900-1200$} & \multirow[b]{2}{*}{$1200-1500$} & \multirow[b]{2}{*}{$1500-1800$} & \multirow[b]{2}{*}{$1800-2100$} & \multicolumn{2}{|l|}{ Hours } & \multirow[b]{2}{*}{$0300-0600$} & \multirow[b]{2}{*}{$\begin{array}{l}\text { Overall in } \\
\text { a day }\end{array}$} \\
\hline & & & & & & $2100-2400$ & $2400-0300$ & & \\
\hline Moving & 24.4 & 25.7 & 14.3 & 20.8 & 14.6 & 17.3 & 8.3 & 15.0 & 17.6 \\
\hline Resting & 60.0 & 39.7 & 56.0 & 52.0 & 66.6 & 65.8 & 73.8 & 65.4 & 59.9 \\
\hline Feeding & 0.5 & 16.1 & 14.3 & 15.8 & 0 & 0 & 0 & 0 & 5.9 \\
\hline Agnostic behaviour & 3.7 & 5.8 & 4.2 & 2.5 & 5.1 & 4.2 & 4.9 & 4.1 & 4.4 \\
\hline Reproductive behaviour & 1.9 & 2.3 & 1.9 & 1.6 & 3.8 & 2.0 & 4.0 & 4.5 & 2.6 \\
\hline Others & 9.5 & 10.4 & 9.3 & 7.3 & 9.9 & 10.7 & 9.0 & 11.1 & 9.6 \\
\hline
\end{tabular}

Table 2. Time activity pattern (percent time spent) of the old male Binturong at the AAZP, Vandalur during December 1995 to February 1996.

\begin{tabular}{|c|c|c|c|c|c|c|c|c|c|}
\hline \multirow[t]{2}{*}{ Activity } & \multirow[b]{2}{*}{$0600-0900$} & \multirow[b]{2}{*}{$0900-1200$} & \multirow[b]{2}{*}{$1200-1500$} & \multirow[b]{2}{*}{$1500-1800$} & \multirow[b]{2}{*}{$1800-2100$} & \multicolumn{2}{|l|}{ Hours } & \multirow[b]{2}{*}{$0300-0600$} & \multirow[b]{2}{*}{$\begin{array}{l}\text { Overall in } \\
\text { a day }\end{array}$} \\
\hline & & & & & & $2100-2400$ & $2400-0300$ & & \\
\hline Moving & 12.8 & 13.5 & 8.9 & 17.3 & 8.5 & 8.5 & 5.1 & 3.9 & 8.8 \\
\hline Resting & 69.7 & 44.5 & 61.3 & 55.1 & 72.2 & 78 & 76.7 & 79.6 & 67.5 \\
\hline Feeding & 0.8 & 16.8 & 19.5 & 20.7 & 0 & 0 & 0 & 0 & 7.2 \\
\hline Agnostic behaviour & 5.9 & 7.8 & 3.5 & 2.1 & 6.3 & 6.5 & 4.5 & 3.2 & 4.9 \\
\hline Reproductive behaviour & 0.8 & 1.3 & 0.8 & 0.7 & 2.2 & 0 & 1.8 & 0 & 1.7 \\
\hline "Others" & 10 & 16.1 & 6.0 & 4.1 & 10.8 & 7.0 & 11.9 & 13.3 & 9 \\
\hline
\end{tabular}

Table 3. Time activity pattern (percent time spent) of the young male Binturong at the AAZP, Vandalur during December 1995 to February 1996.

\begin{tabular}{|c|c|c|c|c|c|c|c|c|c|}
\hline \multirow[t]{2}{*}{ Activity } & \multirow[b]{2}{*}{$0600-0900$} & \multirow[b]{2}{*}{$0900-1200$} & \multirow[b]{2}{*}{$1200-1500$} & \multirow[b]{2}{*}{$1500-1800$} & \multirow[b]{2}{*}{$1800-2100$} & \multicolumn{2}{|l|}{ Hours } & \multirow[b]{2}{*}{$0300-0600$} & \multirow[b]{2}{*}{$\begin{array}{l}\text { Overall in } \\
\text { a day }\end{array}$} \\
\hline & & & & & & $2100-2400$ & $2400-0300$ & & \\
\hline Moving & 28.2 & 27.5 & 15.4 & 23.6 & 16.2 & 20.7 & 9.1 & 18.3 & 19.7 \\
\hline Resting & 54.6 & 39.8 & 57.5 & 58.4 & 66.1 & 60.0 & 70.1 & 50.5 & 57.2 \\
\hline Feeding & 1.0 & 16.7 & 10.6 & 11.1 & 0.0 & 0.1 & 0 & 0 & 5.0 \\
\hline Agnostic behaviour & 5.1 & 2.5 & 6.6 & 3.2 & 6.7 & 5.2 & 6.3 & 8.3 & 5.5 \\
\hline Reproductive behaviour & 2.1 & 3.7 & 3.5 & 2.3 & 2.9 & 3.3 & 4.2 & 7.8 & 3.7 \\
\hline Others & 9.0 & 9.8 & 6.4 & 1.4 & 8.1 & 10.7 & 10.3 & 15.1 & 8.9 \\
\hline
\end{tabular}


Table 4. Time activity pattern (percent time spent) of the female Binturong at the AAZP, Vandalur during December 1995 to February 1996.

\begin{tabular}{|c|c|c|c|c|c|c|c|c|c|}
\hline \multirow[t]{2}{*}{ Activity } & \multirow[b]{2}{*}{$0600-0900$} & \multirow[b]{2}{*}{$0900-1200$} & \multirow[b]{2}{*}{$1200-1500$} & \multirow[b]{2}{*}{$1500-1800$} & \multirow[b]{2}{*}{$1800-2100$} & \multicolumn{2}{|l|}{ Hours } & \multirow[b]{2}{*}{$0300-0600$} & \multirow[b]{2}{*}{$\begin{array}{l}\text { Overall in } \\
\text { a day }\end{array}$} \\
\hline & & & & & & $2100-2400$ & $2400-0300$ & & \\
\hline Moving & 29.6 & 32.0 & 18.5 & 23.2 & 18.9 & 22.8 & 11.5 & 20.7 & 22.1 \\
\hline Resting & 53.5 & 34.5 & 56.4 & 54.1 & 62.5 & 59.5 & 68.1 & 56.7 & 55.6 \\
\hline Feeding & 0.3 & 16.7 & 13.3 & 15.8 & 0 & 0 & 0 & 0 & 5.8 \\
\hline Agnostic behaviour & 2.3 & 6.7 & 2.7 & 2.3 & 3.7 & 1.0 & 3.3 & 5.3 & 3.4 \\
\hline Reproductive behaviour & 3.8 & 3.0 & 2.1 & 4.6 & 5.2 & 2.7 & 5.4 & 5.1 & 4.1 \\
\hline Others & 10.5 & 7.1 & 7.0 & 0 & 9.7 & 10.7 & 11.7 & 12.2 & 9.0 \\
\hline
\end{tabular}

Table 5. Enclosure use of different sex classes of Binturong at the AAZP, Vandalur during December 1995 to February 1996.

\begin{tabular}{|c|c|c|c|c|c|c|c|c|c|c|c|c|c|c|c|}
\hline Animal & F1\% & F2\% & F3\% & $\mathrm{F} 4 \%$ & F5\% & F6\% & F7\% & F8\% & F9\% & $\mathrm{C} 1 \%$ & $\mathrm{C} 2 \%$ & W\% & $\mathrm{S} \%$ & Total\% & $\mathrm{H}^{\prime}$ \\
\hline Old male & 1.6 & 2.6 & 2.9 & 1.5 & 10.3 & 1.6 & 5.1 & 2.1 & 11.3 & 34.9 & 25.9 & 0 & 0 & 100 & 1.8292 \\
\hline Young male & 0 & 1.8 & 11.8 & 2.5 & 3.9 & 1.3 & 8.2 & 1.1 & 1.4 & 29.2 & 25.7 & 4.5 & 8.3 & 100 & 1.9691 \\
\hline Female & 0 & 0 & 43.3 & 1.3 & 1.6 & 2.3 & 17.2 & 3.1 & 4.8 & 9.9 & 8.9 & 4.4 & 2.7 & 100 & 1.8146 \\
\hline
\end{tabular}

(See "Materials and Methods" for the description of the parts of the enclosure. Values are percent use of various parts)

\section{Enclosure use}

Pattern of enclosure use by the binturongs at AAZP has been given in table 5. All the three animals showed more or less similar diversity of enclosure use as their diversity (H') values were $1.8292,1.9691$ and 1.8146 for the old male, young male and young male for $\mathrm{Cl}$ and $\mathrm{C} 2$ sites. This suggested that the two males must be separated. The female used F3 more than the other places. Such a site fidelity might perhaps be due to inadequate spacing in the enclosure.

\section{Food and feeding}

The food ration for the binturongs at AAZP were as follows Apple - 3; Banana - 12; Orange - 3; Tomoto - 150 g; Carrot 250g; Cabbage - 250g; Beef - 250g per animal.

The diet apparently did not meet the nutritive requirements as evidenced from the following accounts on the food and feeding of binturongs in the Liberec Zoo (Bulir, 1972) and Washington Zoo (Xanten et al., 1974). According to Bulir (1972) at the Liberec Zoo "Fully grown binturongs are fed once per day on
$0.5 \mathrm{~kg}(1 \mathrm{lb})$ raw cut meat and $0.5 \mathrm{~kg}$ (1lb) fruit - mainly apples and pears. In summer they are fed with plums, cherries and apricots. This diet is supplemented in winter with bananas and preserved fruits. Each binturong also receives one tablespoon of Glucopur (glucose) per day in fruit. Milk in which sponge fingers or rolls and an egg have been dissolved is provided for them to drink and from time to time multi-vitamin preparations are added." At the National Zoological Park, Washington, U.S.A., "each adult binturong receives whole banana, one quarter apple, one quarter orange, one shredded carrot and $227 \mathrm{~g}$ raw feline diet per day. In addition, twice a week they are given 12 mice and once a week two oxtails" (Xanten et al., 1976). So, the diet of the binturongs at AAZP should be suitably improved, based on their nutritive requirements and on earlier reports with reference to other zoos where there were impressive records of binturong breedings (Bulir, 1972; Kuschinski, 1974; Xanten et al., 1976).

\section{Management suggestions}

1. An outdoor enclosure of at least $5 \times 5 \times 5 \mathrm{~m}$ should be annexed 
to the present indoor glass viewed enclosure.

2. The environment of both the outdoor and indoor compartments should be enriched by providing branches simulating their natural forest environments. Additional wooden nest boxes and wooden shelves may be provided.

3. The temperature and humidity levels at the indoor compartment are too high and so steps must be taken for proper ventilation of the indoor compartment.

4. Frequent fighting between the two males indicate that they must be separated.

5. The female and young male must be kept in separate adjoining enclosures until their behaviour shows signs that they are ready to be put together and close monitoring of them after introduction.

6. The diet of the binturongs should be improved based on scientific consideration.

\section{Acknowledgement}

We greatfully acknowledge Mr. M. Jagannatha Rao, I.F.S., then Deputy Director, AAZP, Vandalur for his co-guidance and encouragement of this work; to the Tamil Nadu Forest Department for permission; and to the biologists of the Zoo.

\section{References}

Altman, J. (1974). Observation study of behaviour sampling methods. Behaviour 49(34): 227-265.

Bulir, L. (1972). Breeding Binturongs Arctictis binturong at Liberec Zoo. International Zoo YearBook 12: 117-118.

Gensch, W. (1963). Successful rearing of the Binturong Arctictis binturong Raffi. International Zoo YearBook 4: 79-80.

Kleiman, D.G. (1974). Activity rhythms in the Giant Panda Ailuropoda melanoleuva: an example of the use of check sheets for recording behaviour data in zoos. International Zoo YearBook 14.

Kuschinski, L. (1974). Breeding binturongs Arctictis binturong at Glasgow Zoo. International Zoo YearBook 14: 124-126.

Prater, S.H. (1971). The book of Indian Animals. Oxford University Press, Bombay, 324pp.

Roberts, M. (1989). Environmental correlates of management and reproductive success in the North American Red Panda population. Pp. 129-152. In: Glatston, A.R. (ed.), Red Panda Biology, SPB Academic Press, The Hague.

Shannon, C.E. and W. Weiner (1949). The mathematical theory of communication. University of Illinios Press, Urbana, 117 pp.

Xanten, W.A., H. Kafka and E. Olds (1976). Breeding the Binturongs, Arctictis binturongs at National Zoological Park, Washington. International Zoo YearBook 16: 117-118. 